\title{
Influence of stirring velocity and current density on electrodeposition of Zn-Fe-Mo alloys
}

\author{
Mariana S. Hori, Josiel M. Costa, Ambrósio F. A. Neto
}

\begin{abstract}
This work realized varied electrodeposition experiments to obtain $\mathrm{Zn}$-Fe-Mo alloys submitted to different operation conditions. Studies of electrodeposition and characterization were realized to evaluate the current density and catodic rotation influence on the coatings.
\end{abstract}

\section{Keywords: \\ Electrodeposition, Zn-Fe-Mo, alloys.}

\section{Introduction}

Zinc alloys are commonly used as coating material and their properties can be improved by the codeposition of other metals, according to the needed characteristics. The alloys from molybdenum present high corrosion resistance and thermal conductivity, good endurance and ferromagnetic properties. As reported on literature [1] about the ternary alloy from zinc, cobalt and molybdenum, the last metal has afforded a positive effect in the corrosion resistance, due to its property to form oxides in the surface of the coating. The replacement of cobalt with iron - a metal that also induces the deposition of molybdenum - could result in satisfactory properties as well. The present work has the objective to evaluate the electrodeposition of alloys from Zn-Fe-Mo, involving techniques of electrodeposition and characterization of it, based on the performance of experiments in a system of electrolytic bath.

\section{Results and Discussion}

The parameters evaluated affected directly in the Faradaic efficiency, homogeneity and morphology of the deposits. The EDS analysis indicated that alloys applied from 10 to $30 \mathrm{~mA} \cdot \mathrm{cm}^{-2}$ have led to higher deposition efficiencies. Kosugi et al. [2], in their turn, observed that $10 \mathrm{~mA} . \mathrm{cm}^{-2}$ also resulted in significant efficiencies. Furthermore, the EDS analysis also revealed that at 45 rpm, a coating deposited at $10 \mathrm{~mA} \cdot \mathrm{cm}^{-2}$ contained 0,5 wt.\% Mo, smaller than at $50 \mathrm{~mA} . \mathrm{cm}^{-2}$, which contained 5 wt.\% Mo. This increment in the percentage of the noble metal probably induces the surface to become smoother and more homogeneous, as shown in Figure 1. Szczygiel et al. [3] observed a very similar behavior in the alloy when in presence of molybdenum.

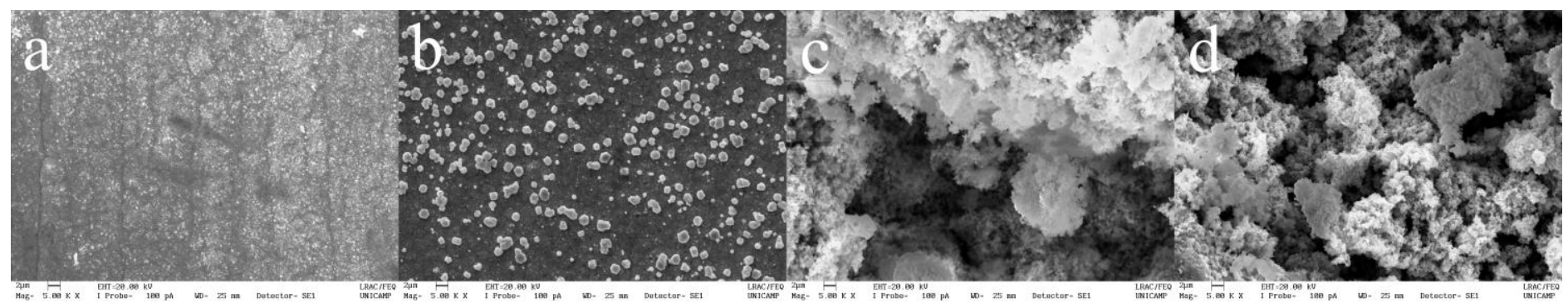

Figure 1. SEM micrographs of Zn-Fe-Mo alloys

A study of momentum influence by the catodic rotation also was realized. It compared the real deposition rate $(\mathrm{Wr})$ with the deposition rate obtained by the forced convection applied on the system (WA). Table 1 shows the results of the experiments submitted to the lowest and highest catodic rotation, respectively.

Table 1. Theoretic and real deposition rates

\begin{tabular}{|c|c|c|c|}
\hline Experiment & Specie & Wa $\left[\mathrm{g} / \mathrm{cm}^{2}\right]$ & $\mathrm{Wr}\left[\mathrm{g} / \mathrm{cm}^{2}\right]$ \\
\hline \multirow{3}{*}{$1(9 \mathrm{rpm})$} & $\mathrm{Zn}$ & 6,62 & 21,88 \\
& $\mathrm{Fe}$ & 0,22 & 0,73 \\
& $\mathrm{Mo}$ & 1,55 & 0,42 \\
\hline \multirow{3}{*}{$2(51 \mathrm{rpm})$} & $\mathrm{Zn}$ & 37,42 & 51,95 \\
& $\mathrm{Fe}$ & 1,251 & 1,73 \\
& $\mathrm{Mo}$ & 0,88 & 0,98 \\
\hline
\end{tabular}

As observed on Table 1, rotation contributes significantly to the system mass transference, because the lowest velocity also presented the lowest influence on the deposition and the highest rotation contributed to the highest deposition.

\section{Conclusion}

The evaluated parameters affected directly on the current efficiency, morphology and composition of the ternary alloy. Fluid dynamics analysis showed that the catodic rotation has significant influence on the electrodeposition of the metals.

Acknowledgement

To PIBIC/CNPQ and FAPESP for the financial support.

\footnotetext{
${ }^{1}$ Winiarski, J; Tylus, W; Szczygiel, B. Appl. Surf. Sci. 2016, 455, 364.

${ }^{2}$ Kosugi, D.; Hagio, T.; Kamimoto, Y.; Ichino, R. Coatings, 2017, 235, 7.

${ }^{3}$ Szczygieł, B.; Laszczyńska, A.; Tylus, W. Journal of Alloys and Compounds $2012,85,530$
} 